\title{
ESTIMATION OF SUSPENDED SEDIMENT TRANSPORT AMOUNT IN THE STREAMS FLOWING INTO THE SAPANCA LAKE BASIN
}

\section{TEMEL TEMIZ1 ${ }^{1}$, EMRAH DOGAN ${ }^{2}$, ADNAN ONER $^{1}$, MÜCAHIT OPAN ${ }^{1, *}$ and OSMAN SONMEZ ${ }^{2}$}

\author{
${ }^{1}$ Department of Civil Engineering, Faculty of Engineering, Kocaeli University,Turkey. \\ ${ }^{2}$ Department of Civil Engineering, Faculty of Engineering, Sakarya University,Turkey. \\ *E-mail: opanmucahit@yahoo.com
}

\begin{abstract}
This paper is about to estimate the suspended sediment transport amount in the streams flowing into the Sapanca Lake Basin. There are 12 subsidiary streams flowing into the Sapanca Lake Basin. With the aim of estimating the suspended sediment transport in 2012-204 in these subsidiary streams, measurements belonging the parameters such as level, cross sectioning, flow rate, temperature and suspended sediment were made monthly. Along the measurement period, weather conditions were above seasonal normal and precipitations decreased. In order to estimate the suspended sediment amount by using results of the measurement obtained, Artificial Neuron Network (ANN), Sediment Rating Curve (SRC) and Multiple Linear Regression (MLR) models were used for different scenarios. It was seen that artificial neuron networks yielded the most accurate results among the models.
\end{abstract}

Keywords:Sapanca Lake Basin, Suspended Sediment amount, Artificial Neuron Networks, Sediment Rating Curve, Multiple Linear Regression

\section{INTRODUCTION}

Sapanca Lake Basin that is one of the internal water basins of Marmara Region is an important water source that extends between Sakarya River and Izmit Gulf. It is located on the transportation network that connects Anatolia to Europe. The Lake is fed by the small streams coming from the mountains in its north and south and sources in the lake bottom. It is drinking and running water sources of surrounding settlements and big industries around it. Sapanca Lake is affected from contaminating sources coming from the surrounding settlement areas. Also, contamination risk of the lake has been increased as a result of that it has become a basis for automotive industry, sub-industry and food industry in the recent times. This situation has been restricting beneficial use (drinking and running, irrigation, recreactive use, etc.) opportunities [15].

In the study that was carried out concerning to sediment characteristics, load and reservoir sedimentations along with the hydraulic principles of the sedimentation, Karakaya Dam was selected as the implementation field and modified Einstein methods were used along with Meyer - Peter and Müller [7].The changes that have occurred in Lower Sakarya River after construction of Gökçekaya Dam in 1975 were reviewed and it was seen that flood peak flow rates in Lower Sakarya River decreased about 30-50\% after this period and also suspended sediment transport amounts decreased about 30-50\% after construction of Gökçekaya 
Dam and some pittings were occurred in the river bed [14]. Different results were obtained for different scenarios on single and double layer pamolare model that was established with the aim of determining the water quality in Sapanca Lake [12].

The modeling was made in HECRAS packet program by using values of Electric Power Survey and Examination Administration measurement on Gediz River and State Hydraulic Works Administration (DSI) data and sediment load calculation methods were calculated according to Yang, Engelund Hansen, Laursen, Ackers White, Meyer Peter-Müller, Toffaleri [13]. The suspended sediment efficiency calculated with empirical methods was compared with the one that was applicable for the basin among the empirical methods after reviewing precipitation-flow and sediment relations of Hurman Brook [1]. In the study concerning to comparison of the suspended sediment amounts measured in specific stations of Firat Basin with the results obtained from relations used for calculation of sediment amounts in the rivers; while it was stated that Meyer-Peter-Müller relation may used in some stations securely, it was seen that Garde Albertson relation is valid in some stations [9]. A model was generated by using 13 years AGI data supplied from EIE for monitoring the suspended sediment transport in Korubaş1-Arak stream with analytic methods [10]. The direct measurements of suspended sediment amount in the rivers that were made on the observation stations were improved with genetic algorithm as a result of the study at which sediment rating curve, soft computing methods and approaches based on empirical studies and it was seen that Brooks method may be applied in Gediz Basin [18]. The problem of suspended sediment transport was resolved with finite volume method kinetic fluctuation approach and also open and closed solution schemes were reviewed in terms of balanced and unbalanced transport cases for suspended sediment transport modeling [6].

The methods such as Artificial neuron networks (ANN) that are referred to as soft computing methods, Mamdani and Sugeno fuzzy logic (Mamdani- BM, Sugeno-BM), adaptive neural fuzzy system (ANFS) were used for estimation of suspended sediment amount in Lower Sakarya River [5]. Upper Büyük Menderes River Lower Basin and Banaz Brook Lower Basin were selected and sediment estimation methods were developed that have different input structure in these basins with artificial neuron networks method [11]. The models based on artificial neuron networks were developed for monthly sediment amount and four different artificial intelligence methods were used [8]. Along with various regression methods, ANN model was used for bed load calculation that is prepared with the aim of determining the bed load transport and at which morphological, hydrometric and physiological variables of the basin are defined as a function for 12 different rivers. Gediz, Küçük Menderes and Büyük Menderes Rivers that are the main water sources of Aegean Region were reviewed in terms of suspended sediment transport. Within the light of scenarios generated, empirical approached were tried for four station in the region along with sediment ration curve, regression and artificial intelligence methods [17]. As a result of the study that was carried out on the water quality of main tributary of Harşit brook, water quality classification was done and it was revealed whether its water is drinkable of not. Estimation of suspended sediment concentration (SSC) based on turbidity, total iron and total chrome parameters were made with various regression analyses and artificial neuron networks (ANN) methods [4]. Artificial neuron networks method was used in estimation of suspended sediment amount. For sediment estimation, flow data belonging to Yamula observation station in Kızılırmak River in 1973-2003 were used as input parameter and various ANN models were developed [16].

In this paper, measurements belonging to flow rate, temperature and suspended sediment parameters were made in 2012- 2014 in 12 subsidiarystreams flowing into the Sapanca Lake Basin in order to estimate the 
suspended sediment amount in the streams flowing into the Sapanca Lake Basin. Artificial Neuron Networks (ANN), Sediment Rating Curve (SRC) and Multiple Linea Regression (MLR) models were developed in order to estimate the suspended sediment transport by using results of the measurements obtained. Three different scenarios were generated as single input-single output, four inputs-single output and eight inputs-single output for these models. The results obtained from these scenarios were compared.

\section{METHODS}

\section{Artificial Neural Networks}

Artificial Neural Networks (ANNs) consist of large number of processing elements with their interconnections. ANNs are basically parallel computing systems similar to biological neural networks. They can be characterized by three components: Neurons, weights (connection strength) and an activation (transfer) function.

Artificial neural networks (ANNs) modeling is a relatively new technique in hydraulic and hydrology engineering. It is essentially a "black box" operation linking input data to output data using a particular set of nonlinear basis functions. Since ANN modeling is a nonlinear statistical technique, it can be used to solve problems that are not amenable to conventional statistical and mathematical methods. In the past few years there has been constantly increasing interest in neural networks modeling in different fields of hydrology engineering.

The basic unit in the artificial neural network is the neuron. Neurons are connected to each other by links known as synapses, associated with each synapse there is a weight factor. Usually neural networks are trained so that a particular set of inputs produces, as nearly as possible, a specific set of target outputs. The most commonly used ANN is the three-layer feed-forward ANN [2]. In feed-forward neural networks architecture, there are layers and nodes at each layer. Each node at input and inner layers receives input values, processes and passes to the next layer. This process is conducted by weights. Weight is the connection strength between two nodes. The numbers of neurons in the input layer and the output layer are determined by the numbers of input and output parameters, respectively. In the present study the feed-forward artificial neural networks are used. The term "feed-forward" means that a node connection only exists from a node in the input layer to other nodes in the hidden layer or from a node in the hidden layer to nodes in the output layer; and the nodes within a layer are not interconnected to each other.

Commonly, neural network modeling follows these steps: database collection; analysis and preprocessing of the data; training of the neural network. The latter includes the choice of architecture, training functions, training algorithms and parameters of the network; testing of the trained network; and using the trained neural network for simulation and prediction. The model developed here has adopted these steps.

\section{Multiple Linear Regression (MLR)}

If it is assumed that the dependent variable $\mathrm{Y}$ is affected by $\mathrm{m}$ independent variables $\mathrm{X}_{1}, \mathrm{X}_{2}, \ldots, \mathrm{X}_{\mathrm{m}}$ and a linear equation is selected for the relation among them, the regression equation of $\mathrm{Y}$ can be written as:

$$
y=a+b_{1} x_{1}+b_{2} x_{2}+\ldots+b_{m} x_{m}
$$

$\mathrm{y}$ in this equation shows the expected value of the variable $\mathrm{Y}$ when the independent variables take the values $\mathrm{X}_{1}=$ $\mathrm{x}_{1}, \mathrm{X}_{2}=\mathrm{x}_{2}, \ldots, \mathrm{X}_{\mathrm{m}}=\mathrm{x}_{\mathrm{m}}$ 
The regression coefficients $a, b_{1}, b_{2}, \ldots, b_{m}$ are evaluated, similar to simple regression, by minimizing the sum of the eyi distances of observation points from the plane expressed by the regression equation [3]:

$$
\sum_{i=1}^{N} e_{y i}^{2}=\sum_{i=1}^{N}\left(y_{i}-a-b_{1} x_{1 i}-b_{2} x_{2 i}-b_{m} x_{m i}\right)^{2}
$$

In this study, the coefficients of the regressions were determined using least square method.

\section{Sediment Rating Curve (SRC)}

Sediment rating curve equation which depends on relationship between suspended sediment load and water discharge is given,

$$
Q_{s}=a Q^{b}
$$

where, $\mathrm{Q}=$ water discharge $\left(\mathrm{m}^{3} / \mathrm{s}\right) ; \mathrm{Q}_{\mathrm{s}}=$ suspended sediment load (ton/day) and a and $\mathrm{b}=$ constants which depend on river characteristics.

\section{MATERIALS}

\section{Sapanca Lake Basin and Streams Flowing into the Basin}

Sapanca Lake takes places at $40^{\circ} 41^{\text {ee }}$ to $40^{\circ} 44^{\text {ee }}$ northern latitudes and $30^{\circ} 09^{\text {ee }}$ to $30^{\circ} 20^{\text {ee }}$ eastern longitudes at $20 \mathrm{~km}$ eastern of Izmit Gulf in Marmara Region. The lake within the borders of Sakarya and Kocaeli provinces is at $30 \mathrm{~m}$ elevation from the sea level. It is a fresh water lake in a tectonic hollow and reaches to Adapazar1 Lowland as a continuation of Izmit Gulf. Eastern end of the lake is $5 \mathrm{~km}$ far away to Sakarya River and $20 \mathrm{~km}$ far away from Izmit Gulf. Long axis of Sapanca Lake is at east-west direction and at $16 \mathrm{~km}$ long and short axis of the lake is at south-north direction and its widest place is $6 \mathrm{~km}$. Average depth of the lake is 31-33 $\mathrm{m}$ and maximum depth of the lake is $61 \mathrm{~m}$. Basin field of the lake is $252 \mathrm{~km}^{2}$ and approximately $46 \mathrm{~km}^{2}$ of this field is lake, $150 \mathrm{~km}^{2}$ is forest and remaining part is agricultural and settlement areas. Sapanca Lake forms one of the most significant freshwater sources of the region (SASKI, 2003). Sapanca Lake Basin Location map is shown in Figure 1.

Sapanca Lake is fed by small streams coming from the mountains in its north and south and the sources in the lake bottom. The streams that feed the lake and measurement stations on the streams are shown in figure 2. The lake is mainly fed from the bottom (with groundwater) due to that flow rates of the streams are low and some of these streams dry up in the summer months. As well as the streams flowing into the lake, Carksuyu that is the exit water of the lake and Arifiye Stream that is connected to Carksuyu with seawall channel take place. Length of the Carksuyu is $45 \mathrm{~km}$ and exit from east of Sapanca Lake and gathered into Sakarya River by directing towards the northern east after taking Elmalı Stream, Kocadere and Söğüt Stream from the west. Arifiye Stream is at $5 \mathrm{~km}$ long. Data belonging to some streams are given in Table 1.

\section{Field Measurements}

With the aim of determining the suspended sediment transport on 12 streams that are located in Sapanca Basin, flow rate, suspended sediment and temperature measurements were made in 2012- 2014. The suspended sediment values are as shown in Table 2, flow rate values are shown in Table 3 and temperature values are shown in Table 4.

PMPCM25 propeller type small current meter was used for flow rate measurements and two methods were used for measurement of suspended sediment. The first method is determination of suspended sediment 
concentration in the laboratory by sampling from the river through depth integration method by using US.DH-48 device. The second method is determination the suspended sediment amount directly with Insite IG Model 3150 Portable Suspended Sediment Meter device.

\section{Application of the Models}

Artificial Neuron Networks (ANN), Sediment Rating Curve and Multiple Linear Regression models were developed in order to estimate the suspended sediment transport by using results of the flow rate measurement obtained from the land.

Artificial Neuron Networks (ANN) may be defined as expert systems that are developed with the aim of automatically achieving the skills such as deriving, generating and exploring new information through learning that is a property of human brain without any help. The Sediment Rating curve (SRC) is referred to the method that is produced by using the regression equation correlating the flow rate in the river and streams and riverborne solid matters. Multiple linear regression (MLR) model is a regression equation that is used in the cases that input and output values are more than one.

Number of the measurements done for the modeling and also physical characteristics of all streams are very different from each other. When these cases are taken into consideration, it is hard the models to yield healthy results. Single input-single output, four inputs-single output and eight inputs-single output scenarios were produced for these models. There different models were compared for single input and single output set within the scope of first scenario. The comparison was not made between ANN and MLR models within the scope of second and third scenarios. In the modeling, MATLAB 7.0 programming packet was used.

\section{RESULTS AND DISCUSSIONS}

Artificial Neuron Networks (ANN), Sediment Rating Curve and Multiple Linear Regression models were developed in order to estimate the suspended sediment transport by using results of the measurement. Three scenarios were produced for these models as single input-single output, four inputs-single output and eight inputs-single output. ANN, MLR and SRC models were compared in the first scenario and ANN and MLR models were compared in the second and third scenario.

\section{First scenario (1 input - 1 output)}

The flow rate was selected for the models as input and estimation of the suspended sediment amount was requested from the model as output. The date set belonging to first scenario are shown in the Table. ANN, SRC and MLR models were compared for this scenario.

The test model input and determination results for the second scenario are shown in Figure 3 and 4 according to sediment rating curve and in Figure 5 and 6 according to multiple regression model and in Figure 7 and 8 , respectively according to artificial neuron networks.

The performances of the models are given in Table 8 according to the scenario that was produced as single input and single output. When these results are reviewed, it is seen that the cases at which Mean Square Error (MSE) and Square-root Mean Square Error (SMSE) are near-zero and the values that determination and correlation coefficients are close take place in the scenario method. There are negative results in MLR model that is the second method. Therefore, it seems that it is not possible to use the results obtained even if this 
method yields the best results. When it is reviewed in terms of these approaches, it may be seen that ANN model that is the third method has yielded the best result.

\section{Second scenario (Eight inputs - single output)}

As shown in Table 7, flow rate was selected as input and estimation of the suspended sediment amount was requested from the model as output with eight different parameters. For this scenario, ANN and MLR models were compared.

The test model input and determination results for the second scenario are shown in Figure 9 and 10 according to multiple linear regression model and in Figure 11 and 12, respectively according to artificial neuron network model.

As shown in Table 9, flow rate was selected as input and estimation of the suspended sediment amount was requested from the model as output with four different parameters. For this scenario, ANN and MLR models were compared.

The performances of the models are given in Table 8 according to the scenario that was produced as eight inputs and single output. When these results are reviewed, it is seen that the cases at which MSE and SMSE are near-zero are seen in the first method, the values that determination and correlation coefficients are close take place in the second method.

There are negative results in MLR model that was the first method. Therefore, it may be said that best result was obtained from SRC model among these two methods.

\section{Third scenario (Four inputs - single output)}

As shown in Table 9, flow rate was selected as input and estimation of the suspended sediment amount was requested from the model as output with four different parameters. For this scenario, ANN and MLR models were compared.

According to multiple linear regression model, test model input and determination results are given in Figure 13 and 14 for the scenario and the results for artificial neuron networks model in Figure 15 and 16 , respectively.

According to the scenario that was produced as four inputs-single output, performances of the models are as shown in Table 10. When the results are reviewed, it is seen that the cases at which MSE and SMSE are near-zero and values that determination and correlation coefficients are close take place in the second method. There are negative results in MLR model. When it is reviewed in terms of these approaches, SRC has yielded the best result.

\section{CONCLUSIONS}

In this paper, the measurements belonging to flow rate, temperature and suspended sediment parameters were carried out in order to determine the suspended sediment transport in the streams flowing into the Sapanca Lake Basin in 2012-2014. Artificial Neuron Networks (ANN), Sediment Rating Curve (SRC) and Multiple Linear Regression models were developed in order to estimate the suspended sediment transport by using results of the measurement. Three scenarios as single input-single output, four inputs- single output and eight inputs - single output were produced for these models. The potential of an ANN in estimating suspended sediment load was examined in this paper by comparing the results with those obtained by using the MLR and SRC. Based on the 
comparison results, the ANN technique was found to perform better than the other models. The SRC technique was generally found to be better than the MLR. The MLR has also better estimates. However, it gives some negative values for the lowest value of $\mathrm{Q}_{\mathrm{s}}$ estimation. It is a drawback for the MLR. It may be said that it is not sufficient to explain suspend sediment transport that is very complex as the input parameter in SRC is only flow rate and other hydraulic parameters are not taken into consideration in this model. When the scenarios established with ANN are reviewed, it may be said that the parameters are abounding and these parameter are correlated with the event of sediment transport. Consequently, ANN models have yielded more accurate and reliable results for each scenario compared to other models.

\section{REFERENCES}

1. Aksu, N.(2007). Estimation of Sedimentation with Empirical Methods in Hurman Stream Basin. Master of Science., Institute of Science and Technology, Kahramanmaraş Sütçü Imam University, Turkey.

2. ASCE Task Committee (2000). Artificial neural networks in hydrology. II: Hydrological applications. $J$ Hydrol. Eng. ASCE, Vol. 5, No. 2, pp. 124-137.

3. Bayazit, M. and Oguz, B. (1998). Probability and statistics for engineers. Birsen Publishing House, Istanbul, Turkey.

4. Bayram, A. (2011). Investigation of the seasonal variation of the water quality of the Harşit River and Estimation of Suspended Substance Concentrationwith rtificial Neural Networks Method. PhD, KTUUniversity, Institute of Science and Technology, Trabzon, Turkey.

5. Doğan, E., Sasal, M. and Işık, S.(2005). Suspended sediment load estimation in lower Sakarya river by using soft computational methods. Proceeding of the International Conference on Computational and Mathematical Methods in Science and Engineering, CMMSE, pp. 395-406.

6. Kaya, B. and Gharehbaghi, A.(2012). Modelling transport of solids by finite volume method in the current unstable conditions. Journal of the Faculty of Engineering and Architecture of GaziUniversity, Vol. 27, No. 4, pp. 827-836.

7. Kayhan, B. A. (2001). River and reservoir sedimentation. Kocaeli University, Institute of Science and Technology, PhD, Turkey.

8. Minarecioğlu, N.(2008). Estimation of the carried amount of solids using the artificial intelligence methods $n$ natural waterways. Master of Science, Institute of Science and Technology, Sakarya University, Turkey.

9. Mutlu, M.(2007). A case study For Euphrates Basin and determination of solid content in river basins. Master of Science, Institute of Science and Technology, Harran University, Turkey.

10. Oğuz,. V. (2010). Monitoring and Analytical Methods of Suspended Sediment Movements. Korubaş-Arak, Master of Science, Institute of Science and Technology, Ankara University, Turkey.

11. Ocal, O. (2007). Determination of rainfall-runoff-sediment relations using the artificial neural network algorithm in river basins. Master of Science, Pamukkale University, Institute of Science and Technology, Turkey.

12. Rahmanlar, M. (2009). Modelling Sapanca Lake with One and two layer pamolare model for evaluation of water quality. Master of Science,Institute of Science and Technology, Boğaziçi University, Turkey. 
13. Sahin, Y. (2006). Investigation of sediment transport in the central part of the Gediz River. Master of Science, Institute of Science and Technology, Niğde University, Turkey.

14. Saltabaş, L., Saşal, M., Işık, S. and Doğan, E. (2003). Investigation of current changes in the Lower Sakarya River. Journal of Institute of Science and Technology, Sakarya University, No. 72, pp. 9-15.

15. Temiz, T.(2015). Estimation of the transported amount of suspended solids in the streams fowing into the Sapanca Lake Basin. PhD,Institute of Science and Technology, Kocaeli University, Turkey.

16. Terzi,O. and Baykal, T.(2012). Estimation of the amount of solids with artificial neural networks in rivers: The Kizilırmak River case. SDU International Technologic Science, Vol. 4, No. 3, pp. 8-14.

17. Ulke, A.(2010). Implementation of the empirical regression and artificial intelligence methods for sediment transport in natural rivers of the Aegean Region. PhD, Institute of Science and Technology, Department of Hydraulic, Hydrology and Water Soruces, Dokuz Eylül University, Turkey.

18. Ulke, A.,Ozkul, S. and Gökmen, T. (2011). Estimation of the suspended solids load with the empirical methods for the Gediz River. IMO- Technical Journal, No. 348, pp. 5387-5407. 